\title{
Expert annotation and life-cycle transcriptomics of transcription factors in rust fungi (Pucciniales) highlight the role of cold shock proteins in dormancy exit
}

\author{
Clémentine Louet ${ }^{1}$, Carla Blot ${ }^{1}$, Ekaterina Shelest ${ }^{2}$, Pamela Guerillot ${ }^{1}$, Jérémy Pétrowski ${ }^{1}$, Pascal Frey ${ }^{1}$, Sébastien \\ Duplessis $^{1 *}$ \\ 1. Université de Lorraine, INRAE, IAM, F-54000 Nancy, France \\ 2. School of biological Sciences, University of Portsmouth, King Henry 1 Street, PO1 D2Y, Portsmouth, United Kingdom \\ * corresponding author: Sebastien Duplessis (Sebastien.duplessis@inrae.fr)
}

\begin{abstract}
Fungi of the order Pucciniales are obligate plant biotrophs causing rust diseases. They exhibit a complex life cycle with the production of up to five spore types, infection of two unrelated hosts and an overwintering stage. Transcription factors (TFs) are key regulators of gene expression in eukaryote cells. In order to better understand genetic programs expressed during major transitions of the rust life cycle, we surveyed the complement of TFs in fungal genomes with an emphasis on Pucciniales. We found that despite their large gene numbers, rust genomes have a reduced repertoire of TFs compared to other fungi. The proportions of $\mathrm{C} 2 \mathrm{H} 2$ and Zinc cluster -two of the most represented TF families in fungi- indicate differences in their evolutionary relationships in Pucciniales and other fungal taxa. The cold shock protein (CSP) family showed a striking expansion in Pucciniomycotina with specific duplications in the order Pucciniales. The survey of expression profiles collected by transcriptomics along the life cycle of the poplar rust fungus revealed TF genes related to major biological transitions, e.g. response to environmental cues and host infection. Particularly, poplar rust CSPs were strongly expressed in basidia produced after the overwintering stage suggesting a possible role in dormancy exit. Expression during transition from dormant telia to basidia confirmed the specific expression of the three poplar rust CSP genes. Their heterologous expression in yeast improved cell growth after cold stress exposure, strengthening their implication in dormancy exit. This study addresses for the first time TF involved in developmental transition in the rust life cycle opening perspectives to further explore molecular regulation in the biology of the Pucciniales.
\end{abstract}

Key-words: Melampsora larici-populina, life cycle, basidia, telia, cold stress.

\section{Introduction}

Transcription factors (TFs) are essential for the regulation of expression pathways in eukaryotes by binding genomic DNA in a sequence-specific manner (Charoensawan et al., 2010; Weirauch and Hughes, 2011). TFs are classified according to their DNA-Binding Domains (DBDs) in TF families based on the DBD similarity (Hughes, 2011; Pabo and Sauer, 1992). In fungi, an expansion of TF repertoires was observed in correlation with the genome size, likely explained by a handful of dynamic TF families (i.e. Zn cluster, C2H2 Zn finger and HD-like; Shelest 2008, 2017). Moreover, the comparison across more than 200 fungal genomes determined the presence of approximatively 80 DBD families in fungi, including four fungal-specific families (Shelest, 2017). Several DBD families were associated to regulatory functions of fungal pathogenesis in plant-pathogen interactions, such as sporulation or virulence effector expression (John et al., 2021). Other TFs can be associated to abiotic stress responses; those responsible for temperature stresses are characterized by heat shock (HSDs) or cold shock domains (CSDs). In the latter case, the TFs act as molecular chaperones that destabilize unfavorable secondary structures of mRNAs to facilitate translation after cold shocks (Zhang et al., 2018). CSD proteins (CSPs) are mainly associated with cold adaptation and they function as RNA chaperone with a role in RNA secondary structure stability during cold stress (Chaikam and Karlson, 2010). The structures of CSPs provided evidence for a global conservation of the CSD between prokaryotes and eukaryotes (Chaikam and Karlson, 2010; Heinemann and Roske, 2021) with two consensus RNA-binding motifs (RNP1 and RNP2) mediating RNA binding activity and enhancing the RNA affinity (Landsman, 1992; Nakaminami et al., 2006).

Fungi of the order Pucciniales are major plant pathogens infecting a large diversity of host plants, among which are major crops such as soybean, maize or wheat (Lorrain et al., 2019). The rust diseases caused by these obligate biotrophic pathogens lead to severe loss in agriculture (Figueroa et al., 2018; Godoy et al., 2016). They present singular features such as the capacity to infect one or two alternating hosts (the rust are then termed autoecious or heteroecious respectively) and to form up to five spore 
types through their complex life cycle (Aime and McTaggart, 2021). Through the year, under temperate conditions, rust fungi can also enter in an overwintering stage during which spores become dormant (Duplessis et al., 2021). In its most complex form, the life cycle of heteroecious rust fungi undergoes a variety of developmental processes that include infection of two taxonomically distant host plants with the formation of specialized infection structures (e.g. germinating tubes, appressoria, infection hyphae, haustoria, spore-forming structures and spores). Moreover, the fungus needs to adapt to the infected tissue and bypass the hosts' immune systems. These processes require physiological adjustments to nutrient acquisition in the host plants. Sexual and asexual stages also operate on the different hosts and these stages are marked by highly coordinated events. Finally, transitions to dormancy entry and exit are controlled by environmental signals (Duplessis et al., 2021; Mendgen, 1984). Integration of these various signals and developmental processes likely requires a diversity of finely-tuned TF to orchestrate the different genetic programs at play (Duplessis et al., 2021).

In the past ten years, an increasing number of rust genomes have been sequenced (Aime et al., 2017; Lorrain et al., 2019). Most genomes are collected in the JGI Mycocosm database, which allows to draw comparative studies (Grigoriev et al., 2014). Several tools are available to specifically explore the genomes annotations. So far, no global survey of TF genes was conducted in the order Pucciniales, despite reports of gene family expansions presenting typical DBDs (Aime et al., 2017; Cuomo et al., 2017; Duplessis et al., 2011a). Among rust fungi, Melampsora larici-populina (poplar rust fungus) is a pioneer model for rust genomics with transcriptomic resources that encompass the whole life-cycle - i.e. infection of the two host plants and the five spore types making it possible to study specific gene categories based on life-cycle transcriptomics (Duplessis et al., 2021).

In this study, we analyzed the repertoire of transcription factors in Pucciniales compared to other basidiomycetes and to ascomycetes. We showed that despite a striking global contraction of the TF genes complement in Pucciniales, a few families showed significant expansion in comparison to other taxonomical groups, the most remarkable being the CSD family. Life-cycle transcriptomics in the poplar rust fungus showed that CSPs were specifically highly expressed in basidia produced right after the winter dormancy. After confirming these expression profiles in a dormancy interruption experimental setup, we showed that $M$. laricipopulina CSP (MlpCSP) genes expressed in yeast could improve tolerance to cold stress.

\section{Material and Methods}

\subsection{Genomic resources and annotation}

For genomic analysis, published fungal genomes available in the DoE Joint Genome Institute Mycocosm were used as of the 2021/04/09 (https://mycocosm.jgi.doe.gov/). The TF annotation tables containing PFAM domains were downloaded using the "annotations" track from the JGI Mycocosm for selected taxonomical ranks, i.e. the phyla Ascomycota and Basidiomycota; subphyla Ustilaginomycotina and Pucciniomycotina; and the order Pucciniales. The tables were then filtered from non-TF-like DBDs and non-DBDs. In all comparison analyses, the order Pucciniales and subphyla Ustilaginomycotina and Pucciniomycotina were removed from their respective higher taxonomical ranks, which are thereafter referred to as Other_Pucciniomycotina (i.e. Pucciniomycotina without Pucciniales) and Other_Basidiomycota (i.e. without Ustilaginomycotina and Pucciniomycotina). For each fungal species, the total number of predicted genes and TF-associated domains were collected. CSP sequences were collected as fasta for phylogeny, PCR amplification and cloning (Supplementary Text S1).

\subsection{Transcriptomic resources}

Transcriptomic profiling of $M$. larici-populina was established across its life cycle based on previously published studies transposed to the version 2 of the genome (Guerillot et al., 2021). Briefly, gene expression values were determined for dormant and germinated urediniospores, time course infection of poplar leaves and telia by oligoarrays (Duplessis et al., 2011b; Hacquard et al., 2013) and for basidia, as well as for spermogonia and aecia on larch needles by RNAseq (Lorrain et al., 2018a). Expression values for oligoarrays and RNAseq were normalized separately. For the present study, we extracted expression profiles of $M$. larici-populina TF genes from an open transcriptomic dataset (Supplementary Table S1). The Morpheus tool from the broad institute website (https://software.broadinstitute.org/morpheus/) was used to display normalized transcript expression levels using the $k$-means partitioning method.

\subsection{Fungal material}

Telia from M. larici-populina isolate 93GS3 were produced on leaves of the poplar cultivar Robusta $(P$. deltoides $x P$. nigra) following the procedure described in Pernaci et al. (2014). Briefly, poplar leaves were inoculated by urediniospores at the end of the summer and telia differentiated during autumn in a non-heated greenhouse. Leaves bearing dormant telia were placed outside in natural conditions during winter. Leaves were regularly tested in the lab to ensure that vernalization was reached and then kept at $-3^{\circ} \mathrm{C}$ until further use. Basidia were artificially produced from telia by soaking the leaves in 
water for six hours at room temperature, followed by 96 hours of incubation at $19 \pm 1^{\circ} \mathrm{C}$ on a wet paper towel in 24 $x 24 \mathrm{~cm}$ Petri dishes. Pieces of leaves bearing telia ( $20 \mathrm{mg}$ ) were sampled right before soaking the leaves in water ( $t-$ Oh), after 6 hours immersion in water (t-6h) and after 96 hours of incubation (t-96h). For the later condition, both telia which produced basidia visible as a dense orange mat (t-96h_BSD) and non-vernalized telia which did not produce basidia (t-96h_TEL) were separated.

\subsection{RNA isolation, reverse transcription (RT) and quantitative PCR}

Total RNA was isolated from telia and basidia samples with the RNeasy plant mini kit (Qiagen, Courtaboeuf, France), using RLT buffer with -mercaptoethanol, following manufacturer's recommendations. The RNase-Free DNase Set (Qiagen) treatment was applied to all samples according to the manufacturer's recommendations, to eliminate traces of genomic DNA. Primers were designed for MIpCSP1, MIpCSP2 and MIpCSP3 (Supplementary Table S2) and efficiency for each target sequence ranged between 80 and $99 \%$. First-strand cDNAs were synthesized from $500 \mathrm{ng}$ DNase-treated total RNA by RT with the iScript CDNA synthesis kit (Bio-Rad) in a total volume of 20 $\mu \mathrm{L}$ according to the manufacturer's instructions. For the qPCR amplification, $2 \mu \mathrm{L}$ of one-tenth diluted RT products were amplified in $2 X$ ABsolute GPCR SYBR Green Mix (Thermo Fisher Scientific, Illkirch, France) with $1.6 \mu \mathrm{M}$ of specific primers with an QuantStudio ${ }^{\text {TM }} 6$ Flex system (Applied, Biosystems, Life Technologies, Saint-Aubin, France) in a final volume of $15 \mu \mathrm{L}$. Transcript expression levels were normalized with the reference gene MIp-ELF1a using the $2^{-\Delta C t}$ calculation (Livak and Schmittgen, 2001), and expressed relative to the highest expression level, set at $100 \%$ (Hacquard et al., 2011b).

\section{5. cDNA cloning, yeast transformation and cold stress tolerance assay}

MIpCSP1, MIpCSP2 and MIpCSP3 were amplified from t96h_BSD cDNA using specific primers defined on the M. larici-populina genome sequence (Supplementary Table S2). The PCR-amplified products were digested for 1 $\mathrm{h}$ at $37^{\circ} \mathrm{C}$ with $\mathrm{BamHI} / \mathrm{Xhol}$ and HindIII/Xhol restriction enzymes for MlpCSP1; and MlpCSP2 and MlpCSP3, respectively. Digestion products were purified with the illustra GFX PCR DNA and gel band purification kit (GE Healthcare, Little Chalfont, UK) and were directionally cloned in the yeast expression vector pYES2 (Invitrogen, Thermo Fisher Scientific) carrying the URA3 selection marker driven by the GAL1 promoter; after ligation overnight at $4^{\circ} \mathrm{C}$ with the T4 DNA ligase (New England Biolabs, Evry, France).The sequences of the cloned fragments in the resulting plasmids pYES2::MIpCSP1, pYES2::MIpCSP2 and pYES2::MIpCSP3 were verified by Sanger sequencing (GENEWIZ, Leipzig, Germany). Yeast strain BY4741 (MATa, Ura3 $\Delta 0$, Leu2 $\Delta 0$, His $3 \Delta 1$, Met15 $\Delta 0$ ) grown in YPG medium [1\% $(\mathrm{w} / \mathrm{v})$ yeast extract, $2 \%(\mathrm{w} / \mathrm{v})$ peptone, $2 \%(\mathrm{w} / \mathrm{v})$ glucose] was transformed with each plasmid or with the empty pYES2 plasmid as a control. All transformations were performed according to Gietz and Schiestl (2007). For yeast growth experiments, YNB selective medium $[1 \%(\mathrm{w} / \mathrm{v})$ yeast extract, $2 \%(\mathrm{w} / \mathrm{v})$ peptone, $2 \%(\mathrm{w} / \mathrm{v})$ glucose] supplemented with leucine, histidine, methionine was used. Yeast cells transformed with pYES2 constructs and the empty vector were incubated with shaking for 24 hours at $30^{\circ} \mathrm{C}$ in YNB selective medium as described above. To promote MIpCSP expression, cultures were then adjusted to an equal density (OD600 $=0.4)$ and incubated with shaking for 24 hours at $30^{\circ} \mathrm{C}$ in YNB inductive medium $[1 \%(\mathrm{w} / \mathrm{v})$ yeast extract, $2 \%(\mathrm{w} / \mathrm{v})$ peptone, $2 \%(\mathrm{w} / \mathrm{v})$ galactose] with the amino acids described above. To test the ability of transformed yeast to tolerate cold stress, inducted yeast cells were re-suspended in $2 \mathrm{~mL}$ of YNB inductive medium to equal density $(\mathrm{OD} 600=1)$, placed at $-20^{\circ} \mathrm{C}$ during 3,6 , 9,12 or 24 hours and placed back at $30^{\circ} \mathrm{C}$ for 12 hours of further growth with shaking (Gao et al., 2012). The relative cell densities were measured after the recovering step at $30^{\circ} \mathrm{C}$ (OD600). The experiment was performed in triplicate.

\subsection{Statistical analyses}

Statistical analyses were conducted with $R$ software ( $R$ Core Team, 2018) for comparisons of means between taxonomical groups based on analysis of variance (Anova) or its non-parametric alternative (Kruskal-Wallis test); followed, when necessary, by appropriate BonferroniDunn's post hoc test at the threshold level of $P=0.05$.

\subsection{Phylogenetic analysis of cold-shock proteins}

CSP sequences were selected from a collection of representative genomes in distinct taxonomic families available at the Mycocosm for the order Pucciniales (a single representative genome was used for the species Puccinia graminis f. sp. tritici and Puccinia striiformis f. sp. tritici, respectively, from Duplessis et al. (2011a) and Cuomo et al. (2017)); a selection of three species from other Pucciniomycotina classes (Rhodotorula taiwanensis MD1149 and Microbotryum lychnidis-dioicae p1A1 Lamole from the class Microbotryomycetes, and Mixia osmundae IAM 14324 v1.0 from the class Mixiomycetes); and the unique CSP in Aspergilus nidulans in the phylum Ascomycota as an outgroup. CSP sequences alignment and phylogeny were performed on the Phylogeny website (www.phylogeny.fr) with default parameters in the one click mode (without the Gblock option) combining alignment with Muscle and phylogeny with PhyML (Dereeper et al., 2008). The tree was built with FigTree v1.4.4 (http://tree.bio.ed.ac.uk/software/figtree/) from the exported newick file. 


\section{Results}

3.1. Annotation of fungal TF domains reveals a contraction of the TF repertoire in the order Pucciniales.

In order to have a complete view of the TF category in the order Pucciniales and to compare with other fungi, we took advantage of the updated annotation track at the JGI Mycocosm which compiles a series of 137 PFAMs associated to TF functions. We collected this information for a total of 874 fungal species for which the genomes were published and available for comparative studies (Supplementary Table S3). We performed a curation of this collection of PFAMs based on previous expert annotations (Shelest, 2017, 2008) and ended up with a total of 75 TF PFAMs (Supplementary Table S4). Those excluded lacked a DBD, contained a DBD not associated with a TF function (for instance, those of RNA polymerases), corresponded to general transcription function (e.g. TFIl domains) or were related to plant TF with a low representation in the overall dataset. PFAM with a very low representation among all fungi (less than 10 occurrences found among 874 genomes) were also discarded from the set. A total of 58 TF families were defined from their DBD similarity, corresponding to 480339 TF domains in 874 fungal genomes (Table 1).

The order Pucciniales belongs to the subphylum Pucciniomycotina in the phylum Basidiomycota. In order to compare rust fungal TFs, we set taxonomical groups as follows: Pucciniales $(n=12)$, Other_Pucciniomycotina $(n=13)$, Ustilaginomycotina $(n=28)$, Other_Basidiomycota $(n=233)$ and Ascomycota $(n=588)$. In average, the total number of genes is greater in Pucciniales compared with other fungal groups, i.e. $18280 \pm 1580$ in Pucciniales versus 7788 genes \pm 500 in Other_Pucciniomycotina, 6945 genes \pm 628 in Ustilaginomycotina, 15137 genes \pm 687 in Other_Basidiomycota and 10920 genes \pm 163 in Ascomycota. On the contrary, whereas the numbers of TF domains and total gene tend to increase concomitantly in all taxonomical groups, the number of TF domains tends to slightly drop in the order Pucciniales (Figure 1). These fungi present a significant reduction relative to Ascomycota and Other_Basidiomycota (Kruskal-wallis, Bonferonni-Dunn test; $p$-value $<0.0001$ and $p$-value $<$ 0.05 , respectively), but not to Other_Pucciniomycotina or Ustilaginomycotina. These results clearly indicate differences between the genome evolution of Pucciniales in comparison to other basidiomycetes and ascomycetes, with a marked contraction in the Pucciniales.

\subsection{Comparison of TF families distribution across fungi shows specific evolutionary trajectories in Pucciniales.}

To evaluate whether the difference observed in fungal TF domains distribution is related to specific contraction or expansion of particular TF families, we extracted the families most represented in the whole dataset (Table 2).
The top $10 \mathrm{TF}$ families (83\% of the whole fungal TF domains collection) are shown in Figure 2. The $\mathrm{Zn}$ cluster (28.1\%), Fungal-trans (24.1\%), Zf- $\mathrm{C} 2 \mathrm{H} 2$ (9.8\%), Zf-C3HC4 (6.5\%), and SET (3.3\%) families are predominant. Globally, a similar picture can be observed in all surveyed fungal groups. At the contrary, the order Pucciniales presents a different proportion and the four major families are in order $\mathrm{Zf}-\mathrm{C} 2 \mathrm{H} 2, \mathrm{Zf}-\mathrm{C} 3 \mathrm{HC} 4, \mathrm{Zn}$ cluster and SET (Figure 2A). Moreover, we can see that whereas the $\mathrm{Zn}$ cluster TF dominates in all other fungi, the $\mathrm{Zf}-\mathrm{C} 2 \mathrm{H} 2$ is more represented in the Pucciniales (ratio of $\mathrm{Zf}-\mathrm{C} 2 \mathrm{H} 2 / \mathrm{Zn}$ cluster: 1.75 versus 0.62 in average in other fungi; Figure $2 \mathrm{~B}$ ). This clearly points at different evolutionary relationships between the major families of TFs in Pucciniales and other taxa.

\subsection{Survey of TF families reveals expansion of the CSD family in Pucciniales.}

To see if there are TF families with unusual distribution, we compared the number of TF domains for each TF family among taxonomical groups. There are 13 families that are significantly differentially represented in Pucciniales than in at least one other group (four over-represented and nine under-represented) and most of them differ from one or two groups (Table 3). The CSD family is outstanding in this respect, being significantly over-represented in the Pucciniales and Other_Pucciniomycotina compared with all other fungi (in average 3.8 and 3.2 CSDs per genome in Other_Pucciniomycotina and Pucciniales, respectively, against 0.07 in all other fungi; Figure 3 ). Overall, the Pucciniales TF repertoire does not seem to be marked by major expansions or contractions; only the CSD family shows a significant expansion.

\subsection{Phylogeny analysis of CSPs supports a specific expansion at the root of the order Pucciniales.}

To determine the evolutionary relationship between CSPs from the order Pucciniales, we built a phylogenetic tree for CSPs from representative genomes in this order, a selection of three species from other Pucciniomycotina classes, and a single CSP from the phylum Ascomycota (Aspergilus nidulans) as an outgroup. The Figure 4 presents the phylogenetic tree (combining alignment with Muscle and phylogeny with PhyML) and a specific focus on the CSD alignment based on 33 full-length amino acid sequences (Supplementary Text S1). The phylogeny showed two major branches for the Pucciniomycotina with a clear dissociation between Pucciniales and other Pucciniomycotina. Two subclades (highlighted in red and green in Figure 4) on one branch and one clade (shown in blue in Figure 4) on the other branch, only consisted of Pucciniales. Within these clades, distinct branches of CSPS belonging to the families Melampsoraceae, Coleosporiaceae and Pucciniaceae were retrieved, supporting the taxonomy of rust fungi. The phylogeny 
suggests that an ancient duplication occurred at the root of the Pucciniomycotina, and a specific one at the root of the Pucciniales. Furthermore, subsequent duplications occurred independently in two of the three clades for a few rust species (M. allii-populina, P. triticina). The CSD alignment showed a relative conservation over the 70 amino acids of the domain compared to the outgroup and the RNP1 and RNP2 motifs exhibit higher levels of conservation (Figure 4). To conclude, this phylogenetic comparison indicates that the CSP expansion likely occurred through ancient and conserved duplications followed by a few more recent ones; with the presence of a conserved CSD containing the RNP1 and RNP2 signature motifs.

\subsection{Transcriptomics of the poplar rust fungus highlights specific expression profiles of TFs during its life cycle.}

The poplar rust fungus $M$. larici-populina is the only rust fungus for which a survey of the complete life cycle has been established by transcriptomics, covering stages at which all spore forms are formed. Taking advantage of this dataset (Guerillot et al., 2021), we extracted the expression profiles of 213 genes (among a total of $252 \mathrm{TF}$ genes) belonging to TF families. The missing expression profiles correspond to genes for which expression details were not available from the oligoarrays defined on early versions of the genome. The Figure 5 presents the global expression profiling of the $213 \mathrm{M}$. larici-populina TF genes sorted by k-means clustering (see Supplementary Figure $\underline{\mathrm{S} 1}$ for the expanded view of the global profile and $k$-means clusters). Overall, the expression of most genes was not restricted to a single stage, and only a few clusters were predominantly associated with a spore stage ( $k 3$, basidia) or an infection stage (i.e. $k 2$ in larch and $k 4$ and $k 9$ in poplar). Expression during time course infection on the poplar host was most often associated with the spore types formed before or after infection ( $k 1, k 5, k 6, k 8$ and k10). Interestingly, the k10 cluster corresponds to TF genes expressed at almost all surveyed stages except for early timepoints of poplar infection. Only a limited number of genes showed a specific or preferential expression on a given host, larch ( 2 2; spermogonia and aecia) or poplar ( $k 4, k 7$ and k9; time course infection), or at a given spore stage ( $\mathrm{k} 3$; basidia) (see also Supplementary Figure S2). Similarly, only a few TF families could be evidently assigned to a specific stage, such as the CSD family to basidia or the FAR1 family to $24-48 \mathrm{hpi}$, the earliest infection stages of the poplar time course infection (see Supplementary Figure S1 for profiling according to TF families without grouping). To conclude, this transcriptomic survey allows to derive groups of TF genes coordinately expressed along the poplar rust life cycle and to associate the expression of the FAR1 and CSD families to specific M. larici-populina stages. Particularly, the CSD family is only expressed in basidia, a transient stage formed right after the overwintering period.

\subsection{RTqPCR expression profiling confirms the high induction of poplar rust CSP genes during basidia formation and suggests a role in telia dormancy exit}

In order to validate the specific expression of MIpCSP genes observed in basidia by RNAseq, we performed a RTqPCR experiment with poplar rust telia and basidia produced in laboratory conditions during the fungal dormancy exit. Similar temporal patterns of transcript expression were observed for the three MIpCSP genes (Figure 6) with a relative increase of expression at six hours (telia soaked in water at room temperature) compared with $\mathrm{t}$-Oh (dormant telia collected from environmental conditions after an overwintering period). Significantly higher expression levels were then observed for the three genes in basidia produced from overwintered telia after 96 $\mathrm{h}$ of incubation at $19^{\circ} \mathrm{C}$ compared to telia at previous time points (Anova; $p$-value $<0.001$ for MlpCSP1 and MlpCSP2 and $p$-value $<0.01$ for MIpCSP3). Expression levels of MIpCSP genes in telia that did not produce any basidia after $96 \mathrm{~h}$ of incubation (i.e. full extent of dormancy not reached during winter) were not different from the expression in dormant telia. This result validates the specific expression of MIpCSP genes in basidia and suggests that the expression could contribute to dormancy exit after the vernalization of poplar rust teliospores.

\subsection{Expression of MIpCSP genes in yeast allows cell growth recovery after exposure to cold stress.}

In the absence of any genetic transformation system for the poplar rust, we expressed each of the three $M$. laricipopulina CSP genes in yeast cells to evaluate their functional impact, the yeast genome being deprived of CSP gene. We compared the viability of yeast cells transformed with pYES2::MIpCSP1, pYES2::MIpCSP2 and pYES2::MlpCSP3 plasmids with an empty pYES2 plasmid as a control, after applying different periods of cold stress (i.e. 3 to $24 \mathrm{~h}$ of exposure to $-20^{\circ} \mathrm{C}$ ) followed by a period of $12 \mathrm{~h}$ at an optimal growth temperature of $30^{\circ} \mathrm{C}$ (Figure 7). Before nine hours of cold treatment, no significant difference could be observed between the control and the different constructs (Anova; $p$-value < 0.05). All transformed yeasts were sensitive to freezing with a decrease of cell viability. From 9 to 24 hours of cold exposure, yeast cells carrying the construct PYES2::MIpCSP2 exhibited a significant higher level of cell growth relative to the control. The yeast cells carrying the pYES2::MlpCSP1 and pYES2::MlpCSP3 constructs showed significant higher levels of cell growth from 12 to 24 hours of exposure to cold compared with the control yeast (Anova; $p$-value $<0.05$ ). Altogether, these results indicate that MIpCSP1, MIpCSP2 and MIpCSP3 can all contribute to cold stress tolerance in fungal cells. 


\section{Discussion}

Rust fungi are obligate plant pathogens with a unique biological cycle among eukaryotes marked by an alternation of up to five different spore stages differentiated on one or two different host plants (Lorrain et al., 2019). TFs are key cellular elements to finely tune the regulation of genetic programs underlying developmental transitions influenced by both host and environmental signals (Duplessis et al., 2021). Studies of TFs in rust fungi are scarce. The homolog of $S$. cerevisiae STE12 involved in morphological transitions and sexual development was studied in the wheat stripe rust fungus P. striiformis f. sp. tritici, in which PstSTE12 silencing inhibits the pathogen growth in planta (Zhu et al., 2018). Also, the homeodomain pair HD1 and HD2 which play a critical role during mating in fungi were cloned from the wheat rust Puccinia triticina and were proven to be active when expressed in the heterologous system Ustilago maydis (Cuomo et al. 2017). So far, apart from global surveys in fungi (Shelest, 2017, 2008), no dedicated analysis of TF was conducted in rust fungi. Here, by combining a dedicated annotation of TF genes and transcriptomics in a model rust fungus, we address some biological specificities in rust fungi related to their peculiar life cycle.

A previous survey of the TFome in fungal genomes showed that TF numbers tend to increase with the size of the gene complement (Shelest, 2017). Strikingly, whereas rust fungal genomes present significantly larger gene numbers than other fungi, they present reduced TF repertoires. On the other hand, some TF families have had peculiar evolutionary history. For instance, the proportion of Zf$\mathrm{C} 2 \mathrm{H} 2$ related to $\mathrm{Zn}$ cluster is higher in Pucciniales and Pucciniomycotina when compared to other fungi. The $\mathrm{Zn}$ cluster is the most abundant TF family in fungi and more particularly in younger Ascomycota taxa; and they are associated to a variety of regulatory processes (Shelest, 2017; Weirauch and Hughes, 2011). A future challenge will be to determine which specific $\mathrm{Zn}$ cluster and Zf-C2H2 TF genes have been retained or lost in Pucciniales and whether their regulatory roles and target genes are conserved. Apart from these striking differences, only a handful of gene family expansions or contractions could be observed, with CSPs standing out in this respect. Whereas CSPs are absent from a large majority of ascomycetes and basidiomycetes, they are significantly expanded in the order Pucciniales and in other Pucciniomycotina, which exhibit up to five genes. As our analysis suggests, CSP expansion originates from successive duplications in the subphylum Pucciniomycotina and three types of CSP genes belonging to the same branch can be distinguished in the phylogeny of the order Pucciniales. Fungi of the Pucciniomycotina have been reported in a diversity of ecological habitats, including extreme environments imposing strong abiotic stresses (e.g. artic ice, deep-sea habitats; Aime et al., 2014; Toome-Heller, 2016). Pucciniales that are found in temperate, montane or boreal climates most often display a dormant phase during winter in their cycle (Duplessis et al., 2021). The expansion of CSP genes in Pucciniomycotina suggests a role in their adaptation to cold environment.

Transcriptomics is an approach of choice to decipher TF functions in eukaryotes. By combining different transcriptomic studies conducted in the model rust fungus M. larici-populina (Guerillot et al., 2021), it is possible to specifically survey TF expression along the rust life cycle in order to infer TF functions. As expected for this cellular category, a variety of TF genes from different families are expressed at each life stage. Specific TFs associated with a given stage or with a given host plant can be identified. Interestingly, nearly $80 \%$ of the TFs with the highest expression levels were previously reported as regulators of key virulence pathways in phytopathogenic fungi (John et al., 2021). During time course infection of the poplar host, preferential expression of TF genes can also be associated with early colonization, biotrophic growth or sporulation. Similar profiles were previously described for other categories such as virulence effectors (Duplessis et al., 2011b; Hacquard et al., 2012), and it will be crucial to determine whether specific TF can be assigned to such regulation. Moreover, the expression of only few TF families could be restricted to a given stage. For instance, almost all genes of the FAR1 family show a specific expression at the earliest stages of poplar infection, whereas they are not detected in sporulating spores. At this stage, infection hyphae are colonizing the host mesophyll (Hacquard et al., 2011a). An assumed role of FAR1 is mobilization of intracellular lipid reserves during plant infection by the phytopathogenic fungus Magnaporthe oryzae (bin Yusof et al., 2014). It would be interesting to decipher the exact role of FAR1 at this stage and whether regulation of lipid metabolism also plays a role at this stage of rust infection.

M. larici-populina CSPs exhibit the most remarkable expression profile among TF genes, restricted to the basidia stage with the highest transcript levels across the global expression dataset. Basidia are produced from telia right after overwintering when favorable conditions are met (Duplessis et al., 2021). This stage is transient and basidiospores rapidly differentiate to realize infection on larch, the alternate host of the poplar rust fungus (Hacquard et al., 2011a; Pernaci et al., 2014). Temperature and moisture seem to be crucial factors to exit winter dormancy (Mendgen, 1984). An experimental set-up mimicking dormancy exit confirmed the high expression of the three CSP genes, highlighting their major role in the 
transition from cold to favorable temperatures. The biotrophic status of rust fungi impedes their genetic manipulation and gene functional characterization requires heterologous systems (Bakkeren and Szabo, 2020; Hu et al., 2007; Lorrain et al., 2018b). In order to investigate the role of CSP function, the three MIpCSPS were expressed in yeast cells to assay cold recovery as previously described for other fungi (Fang and Leger, 2010). Yeast cells expressing the different rust CSPs showed an improved growth after exposure at $-20^{\circ} \mathrm{C}$ compared to control yeast devoid of CSP. Here, we show that the three MIpCSPs are highly expressed in basidia and can improve growth of yeast cells after a cold shock. Altogether our results clearly indicate that CSPs are major TFs of the rust life cycle with a role associated to dormancy exit and basidia differentiation. In other eukaryotes a variety of functions have been assigned to CSPs (Heinemann and Roske, 2021). A next challenge will be to determine whether each of the three MIPCSP genes exhibit some specificity or show functional redundancy in the regulation of subsequent cellular processes.

To conclude, by combining functional annotation in rust genomes and life cycle survey in transcriptomics data, we open the way to decipher key regulatory processes in the complex biology of rust fungi. Most often, only infection on the main host is studied in rust fungi precluding the understanding of other stages. Our strategy allows to address for the first time the function of regulatory genes in basidia of rust fungi. Beyond the case of CSPs, other major categories may now be considered for detailed analysis at different stages. Fine dissection of specific rust stages by omics approach should help to better define the genetic programs correlating with TF expression.

\section{Funding}

$\mathrm{CL}, \mathrm{JP}, \mathrm{PF}$ and $\mathrm{SD}$ are supported by the Labex Arbre (Programme Investissement d'Avenir, ANR-11-LABX-000201). $C L$ thesis is funded by the Region Grand Est and the French National Research Agency (ANR-18-CE32-0001, Clonix2D project). ES is funded from Research England's Expanding Excellence in England (E3) Fund.

\section{CRediT authorship contribution statement}

Clémentine Louet: Conceptualization, Methodology, Validation, Formal analysis, Investigation, Resources, Data Curation, Writing - Original Draft, Writing - Review \& Editing, Visualization, Supervision. Carla Blot: Validation, Formal analysis, Investigation, Resources, Data Curation. Ekaterina Shelest: Methodology, Formal analysis, Investigation, Resources, Data Curation, Writing - Review \& Editing. Pamela Guerillot: Methodology, Software, Validation, Formal analysis, Investigation, Resources, Data Curation, Writing - Review \& Editing. Jérémy Pétrowski: Resources. Pascal Frey: Resources, Writing - Review \&
Editing, Funding acquisition. Sébastien Duplessis: Conceptualization, Methodology, Software, Validation, Writing - Original Draft, Writing - Review \& Editing, Visualization, Supervision, Project administration, Funding acquisition.

\section{Declaration of Competing Interest}

The authors declare that they have no known competing financial interests or personal relationships that could have appeared to influence the work reported in this paper.

\section{Acknowledgements}

We would like to thank the Redox team of the UMR IAM for hosting molecular experiments, providing inputs and material as well as for rich discussions along the way. We would like to thank all colleagues who were involved in generating primary poplar rust transcriptomic data that we exploited here.

\section{Appendix A. Supplementary material}

Supplementary Table S1. Expression values of the poplar rust fungus TF genes.

Supplementary Table S2. Primers for cloning and expression analysis of Melampsora larici-populina cold shock domain (MlpCSP) genes.

Supplementary Table S3. List of fungal genomes from JGI.

Supplementary Table S4. List and occurrence of TFS detected in fungal genomes.

Supplementary Figure S1. Expression profiling of Melampsora larici-populina TF genes grouped by k-means ( $k=10$ ) across the life cycle. A. Global expression profile with genes sorted by TF families. B. Global expression profile with genes sorted by k-means. Expression values scale from blue to red represents normalized expression levels from 0 (deep blue) to maximum value (deep red) at each stage. Morpheus (https://software.broadinstitute.org/morpheus)

parameters used for k-means were as follows: one minus pearson's correlation, cluster by rows, number of clusters 10 (1000 iterations). For each gene, the id shown on the right side of the profile indicates the Joint Genome Institute Mycocosm protein-ID number with the associated PFAM and TF family in brackets. The $10 \mathrm{k}$ means are shown on the right side of each profile with $k$ means colors corresponding in A and $\mathrm{B}$. 

available under aCC-BY-NC-ND 4.0 International license.

Supplementary Figure S2. Top 10 most highly expressed Melampsora larici-populina TF genes at each stage of the poplar rust life cycle. The life cycle is shown ordered from stages occurring on the telial host to those occurring on the aecial host. URE and UREg, dormant and germinating urediniospores, respectively; T24 to T168, hours postinoculation in a time course infection series on poplar leaves inoculated with urediniospores; TEL, telia; BSD, basidia; SPG, spermogonia; and AEC, aecia. The top 10 most highly expressed TFs have been grouped according to the life cycle as stage-specific, host-specific or other (not host- or stage-specific) based on the stage where they showed highest expression levels.

Supplementary Text S1. List of cold-shock amino-acid sequences used in this study.

\section{References}

Aime, M.C., McTaggart, A.R., 2021. A higher-rank classification for rust fungi, with notes on genera. Fungal Systematics and Evolution 7, 21-47. https://doi.org/10.3114/fuse.2021.07.02

Aime, M.C., McTaggart, A.R., Mondo, S.J., Duplessis, S., 2017. Phylogenetics and phylogenomics of rust fungi, in: Advances in Genetics. 267-307. https://doi.org/10.1016/bs.adgen.2017.09.011

Aime, M.C., Toome, M., McLaughlin, David J., 2014. Pucciniomycotina, in: McLaughlin, D.J., Spatafora, J.W. (Eds.), Systematics and Evolution. Springer, Berlin, pp. 271-294. https://doi.org/10.1007/978-3-642-55318-9_10

Bakkeren, G., Szabo, L.J., 2020. Progress on molecular genetics and manipulation of rust fungi. Phytopathology 110, 532543. https://doi.org/10.1094/PHYTO-07-19-0228-IA

bin Yusof, M.T., Kershaw, M.J., Soanes, D.M., Talbot, N.J., 2014. FAR1 and FAR2 regulate the expression of genes associated with lipid metabolism in the rice blast fungus Magnaporthe $\begin{array}{llll}\text { oryzae. PLoS ONE 9, } & & \end{array}$ https://doi.org/10.1371/journal.pone.0099760

Chaikam, V., Karlson, D.T., 2010. Comparison of structure, function and regulation of plant cold shock domain proteins to bacterial and animal cold shock domain proteins. BMB Reports 43, 1-8. https://doi.org/10.5483/BMBRep.2010.43.1.001

Charoensawan, V., Wilson, D., Teichmann, S.A., 2010. Genomic repertoires of DNA-binding transcription factors across the tree of life. Nucleic Acids Research 38, 7364-7377. https://doi.org/10.1093/nar/gkq617

Cuomo, C.A., Bakkeren, G., Khalil, H.B., Panwar, V., Joly, D., Linning, R., Sakthikumar, S., Song, X., Adiconis, X., Fan, L., Goldberg, J.M., Levin, J.Z., Young, S., Zeng, Q., Anikster, Y., Bruce, M., Wang, M., Yin, C., McCallum, B., Szabo, L.J., Hulbert, S., Chen, X., Fellers, J.P., 2017. Comparative analysis highlights variable genome content of wheat rusts and divergence of the mating loci. G3: Genes, Genomes, Genetics 7, 361-376. https://doi.org/10.1534/g3.116.032797

Dereeper, A., Guignon, V., Blanc, G., Audic, S., Buffet, S., Chevenet, F., Dufayard, J.F., Guindon, S., Lefort, V., Lescot, M., Claverie, J.M., Gascuel, O., 2008. Phylogeny.fr: robust phylogenetic analysis for the non-specialist. Nucleic acids research

36 ,

W465-W469. https://doi.org/10.1093/nar/gkn180

Duplessis, S., Bakkeren, G., Hamelin, R., 2014. Advancing knowledge on biology of rust fungi through genomics, in: Advances in Botanical Research. Elsevier Ltd, pp. 173-209. https://doi.org/10.1016/B978-0-12-397940-7.00006-9

Duplessis, S., Cuomo, C.A., Lin, Y.-C., Aerts, A., Tisserant, E., Veneault-Fourrey, C., Joly, D.L., Hacquard, S., Amselem, J., Cantarel, B.L., Chiu, R., Coutinho, P.M., Feau, N., Field, M., Frey, P., Gelhaye, E., Goldberg, J., Grabherr, M.G., Kodira, C.D., Kohler, A., Kues, U., Lindquist, E.A., Lucas, S.M., Mago, R., Mauceli, E., Morin, E., Murat, C., Pangilinan, J.L., Park, R., Pearson, M., Quesneville, H., Rouhier, N., Sakthikumar, S., Salamov, A.A., Schmutz, J., Selles, B., Shapiro, H., Tanguay, P., Tuskan, G.A., Henrissat, B., Van de Peer, Y., Rouze, P., Ellis, J.G., Dodds, P.N., Schein, J.E., Zhong, S., Hamelin, R.C., Grigoriev, I. V, Szabo, L.J., Martin, F., 2011a. Obligate biotrophy features unraveled by the genomic analysis of rust fungi. Proceedings of the National Academy of Sciences 108, 9166-9171. https://doi.org/10.1073/pnas.1019315108

Duplessis, S., Hacquard, S., Delaruelle, C., Tisserant, E., Frey, P., Martin, F., Kohler, A., 2011b. Melampsora larici-populina transcript profiling during germination and timecourse infection of poplar leaves reveals dynamic expression patterns associated with virulence and biotrophy. Molecular Plant-Microbe Interactions 24, 808-818. https://doi.org/10.1094/MPMI

Duplessis, S., Lorrain, C., Petre, B., Figueroa, M., Dodds, P.N., Aime, M.C., 2021. Host adaptation and virulence in heteroecious rust fungi. Annual Review of Phytopathology 59, 17.1-17.20. https://doi.org/10.1146/annurev-phyto020620

Fang, W., Leger, R.J. St., 2010. RNA binding proteins mediate the ability of a fungus to adapt to the cold. Environmental Microbiology 12, 810-820. https://doi.org/10.1111/j.14622920.2009.02127.x

Figueroa, M., Hammond-Kosack, K.E., Solomon, P.S., 2018. A review of wheat diseases-a field perspective. Molecular Plant Pathology 19, 1523-1536. https://doi.org/10.1111/mpp.12618

Gao, C., Jiang, B., Wang, Y., Liu, G., Yang, C., 2012. Overexpression of a heat shock protein (ThHSP18.3) from Tamarix hispida confers stress tolerance to yeast. Molecular Biology Reports 39, 4889-4897. https://doi.org/10.1007/s11033-011-1284-2

Gietz, R.D., Schiestl, R.H., 2007. Yeast transformation by the LiAc/SS carrier DNA/PEG method. Methods in Molecular Biology 2, 31-34. https://doi.org/10.1007/978-1-4939-13633_1

Godoy, C.V., Seixas, C.D.S., Soares, R.M., Marcelino-Guimarães, F.C., Meyer, M.C., Costamilan, L.M., 2016. Asian soybean rust in Brazil: past, present, and future. Pesquisa Agropecuaria Brasileira 51, 407-421. https://doi.org/10.1590/S0100204X2016000500002

Grigoriev, I. V, Nikitin, R., Haridas, S., Kuo, A., Ohm, R., Otillar, R., Riley, R., Salamov, A., Zhao, X., Korzeniewski, F., Smirnova, T., Nordberg, H., Dubchak, I., Shabalov, I., 2014. MycoCosm portal: Gearing up for 1000 fungal genomes. Nucleic Acids Research 42. https://doi.org/10.1093/nar/gkt1183

Guerillot, P., Morin, E., Kohler, A., Louet, C., Duplessis, S., 2021. A comprehensive collection of transcriptome data to support life cycle analysis of the poplar rust fungus Melampsora larici-populina.
bioRxiv. 
https://doi.org/10.1101/2021.07.25.453710

Hacquard, S., Delaruelle, C., Frey, P., Tisserant, E., Kohler, A., Duplessis, S., 2013. Transcriptome analysis of poplar rust telia reveals overwintering adaptation and tightly coordinated karyogamy and meiosis processes. Frontiers in Plant Science 4, 456. https://doi.org/10.3389/fpls.2013.00456

Hacquard, S., Joly, D.L., Lin, Y.-C., Tisserant, E., Feau, N., Delaruelle, C., Legué, V., Kohler, A., Tanguay, P., Petre, B., Frey, P., Van De Peer, Y., Rouzé, P., Martin, F., Hamelin, R.C., Duplessis, S., 2012. A comprehensive analysis of genes encoding small secreted proteins identifies candidate effectors in Melampsora larici-populina (Poplar leaf rust). Molecular Plant-Microbe Interactions 25, 279-293. https://doi.org/10.1094/MPMI

Hacquard, S., Petre, B., Frey, P., Hecker, A., Rouhier, N., Duplessis, S., 2011a. The poplar-poplar rust interaction: insights from genomics and transcriptomics. Journal of Pathogens 2011. https://doi.org/10.4061/2011/716041

Hacquard, S., Veneault-Fourrey, C., Delaruelle, C., Frey, P., Martin, F., Duplessis, S., 2011b. Validation of Melampsora larici-populina reference genes for in planta RT-quantitative PCR expression profiling during time-course infection of poplar leaves. Physiological and Molecular Plant Pathology 75, 106-112. https://doi.org/10.1016/J.PMPP.2010.10.003

Heinemann, U., Roske, Y., 2021. Cold-shock domainsAbundance, structure, properties, and nucleic-acid binding. Cancers 13. https://doi.org/10.3390/ cancers 13020190

Hu, G., Kamp, A., Linning, R., Naik, S., Bakkeren, G., 2007. Complementation of Ustilago maydis MAPK mutants by a wheat leaf rust, Puccinia triticina homolog: potential for functional analyses of rust genes. Molecular Plant-Microbe Interactions 20,637-647. https://doi.org/10.1094/MPMI

Hughes, T.R., 2011. Introduction to "a handbook of transcription factors." Subcellular Biochemistry 52, 1-6. https://doi.org/10.1007/978-90-481-9069-0_1

John, E., Singh, K.B., Oliver, R.P., Tan, K.C., 2021. Transcription factor control of virulence in phytopathogenic fungi. Molecular Plant Pathology. https://doi.org/10.1111/mpp.13056

Landsman, D., 1992. RNP-1, an RNA-binding motif is conserved in the DNA-binding cold shock domain. Nucleic Acids Research 20, 2861-2864. https://doi.org/10.1093/nar/20.11.2861

Livak, K.J., Schmittgen, T.D., 2001. Analysis of relative gene expression data using real-time quantitative PCR and the 2$\triangle \triangle C T$ method. Methods 25, 402-408. https://doi.org/10.1006/meth.2001.1262

Lorrain, C., Gonçalves dos Santos, K.C., Germain, H., Hecker, A., Duplessis, S., 2019. Advances in understanding obligate biotrophy in rust fungi. New Phytologist 222, 1190-1206. https://doi.org/10.1111/nph.15641

Lorrain, C., Marchal, C., Hacquard, S., Delaruelle, C., Pétrowski, J., Petre, B., Hecker, A., Frey, P., Duplessis, S., 2018a. The rust fungus Melampsora larici-populina expresses a conserved genetic program and distinct sets of secreted protein genes during infection of its two host plants, larch and poplar. Molecular Plant-Microbe Interactions 31, 695-706. https://doi.org/10.1094/MPMI-12-17-0319-R

Lorrain, C., Petre, B., Duplessis, S., 2018b. Show me the way: rust effector targets in heterologous plant systems. Current Opinion in Microbiology 46, 19-25. https://doi.org/10.1016/j.mib.2018.01.016

Mendgen, K., 1984. Development and physiology of teliospores, in: W Bushnell, A.R. (Ed.), The Cereal Rusts. Cambridge, pp. 375-398. https://doi.org/10.1016/b978-0-12-1484019.50018-2

Nakaminami, K., Karlson, D.T., Imai, R., 2006. Functional conservation of cold shock domains in bacteria and higher plants. PNAS 103, 10122-10127. https://doi.org/10.1073/pnas.0603168103

Pabo, C.O., Sauer, R.T., 1992. Transcription factors: Structural families and principles of DNA recognition. Annual Review of Biochemistry 61, 1053-1095. https://doi.org/10.1146/annurev.bi.61.070192.005201

Pernaci, M., De Mita, S., Andrieux, A., Pétrowski, J., Halkett, F., Duplessis, S., Frey, P., 2014. Genome-wide patterns of segregation and linkage disequilibrium: the construction of a linkage genetic map of the poplar rust fungus Melampsora larici-populina. Frontiers in Plant Science 5, 454. https://doi.org/10.3389/FPLS.2014.00454

Shelest, E., 2017. Transcription factors in fungi: TFome dynamics, three major families, and dual-specificity TFs. Frontiers in Genetics 8, 53. https://doi.org/10.3389/fgene.2017.00053

Shelest, E., 2008. Transcription factors in fungi. FEMS Microbiology Letters 286, 145-151. https://doi.org/10.1111/j.1574-6968.2008.01293.x

Spanu, P.D., 2012. The genomics of obligate (and nonobligate) biotrophs. Annual Review of Phytopathology 50, 91-109. https://doi.org/10.1146/annurev-phyto-081211-173024

Team, R.C., 2018. R: A language and environment for statistical computing (version 3.5.2). R Foundation for Statistical Computing, Vienna, Austria.

Toome-Heller, M., 2016. Latest developments in the research of rust fungi and their allies (Pucciniomycotina), in: Li, D.-W. (Ed.), Biology of Microfungi. Springer, Switzerland, pp. 147168. https://doi.org/10.1007/978-3-319-29137-6_7

Weirauch, M.T., Hughes, T.R., 2011. A catalogue of eukaryotic transcription factor types, their evolutionary origin, and species distribution, in: A Handbook of Transcription Factors. Springer, Dordrecht, pp. 25-73. https://doi.org/10.1007/978-90-481-9069-0_3

Zhang, Y., Burkhardt, D.H., Rouskin, S., Li, G.W., Weissman, J.S., Gross, C.A., 2018. A stress response that monitors and regulates mRNA structure is central to cold shock adaptation. Molecular Cell 70, 274-286. https://doi.org/10.1016/j.molcel.2018.02.035

Zhu, X., Liu, W., Chu, X., Sun, Q., Tan, C., Yang, Q., Jiao, M., Guo, J., Kang, Z., 2018. The transcription factor PstSTE12 is required for virulence of Puccinia striiformis f. sp. tritici. Molecular Plant Pathology 19, 961-974. https://doi.org/10.1111/mpp.12582 


\section{Figures}

Figure 1. Distribution of the number of TF domains according to the number of protein-coding genes in fungal genomes. Each dot represents a species with a color code according to fungal taxonomical groups. Linear trendlines are indicated for each taxonomical group with the same colour-code as for dots and the level of confidence interval (0.95) is represented in grey. Other_Basidiomycota: Basidiomycota excluding the subphyla Pucciniomycotina and Ustilaginomycotina. Other_Pucciniomycotina: Pucciniomycotina excluding the order Pucciniales.

Figure 2. Overview of the proportion of the top $10 \mathrm{TF}$ families in fungal genomes. (A) Pie charts displaying the proportion of the top $10 \mathrm{TF}$ families in fungal taxonomical groups. (B) Ratio comparison of each of the top $10 \mathrm{TF}$ family related to the $\mathrm{Zn}$-cluster family (largest family in Ascomycota and Basidiomycota) for each taxonomical group (average values and standard errors are shown). Other_Basidiomycota: Basidiomycota excluding the subphyla Pucciniomycotina and Ustilaginomycotina. Other_Pucciniomycotina: Pucciniomycotina excluding the order Pucciniales. Tree not to scale according to the fungal phylogeny displayed at the Joint Genome Institute Mycocosm.

Figure 3. Abundance of cold-shock domains (CSDs) across different fungal taxonomic genomes. Each small dot represents a species. Other_Basidiomycota: Basidiomycota excluding the subphyla Pucciniomycotina and Ustilaginomycotina. Other_Pucciniomycotina: Pucciniomycotina excluding the order Pucciniales. The boxplot outliers are indicated as big dots.

Figure 4. Phylogeny and domain conservation of coldshock proteins (CSPs) from selected representative genomes in the Pucciniomycotina and the Pucciniales. The phylogenetic tree of 33 full-length fungal CSPs was constructed using the phylogeny.fr website (alignment with Muscle and phylogeny analysis with PhyML) and drawn with FigTree. The unique CSP from the ascomycete Aspergilus nidulans was used as an outgroup. The three distinct clades containing Pucciniales CSPs are colored and red arrows indicate the three Melampsora larici-populina CSPs. Protein IDs from the Joint Genome Institute Mycocosm are shown on the tree for the different fungal species. The alignment of the cold-shock domain (CSD) is presented next to the tree and amino acid residues are colored according to the level of conservation (red, 100\%; yellow, $80 \%$; and light grey, $60 \%$ ). The RNA-binding motifs RNP1 and RNP2 are indicated by a box according to Prosite.
Figure 5. Global expression profiling of the poplar rust fungus TF genes across its life cycle. Expression levels of 213 TF genes were collected from various life stages and grouped by $k$-means partitioning $(k=10)$. Life stages are organized according to the yearly poplar rust life cycle starting from stages on the telial host, poplar, followed by stages on the aecial host, larch. Color scale from blue to red represents normalized expression levels from 0 to maximum value at each stage. Biological stages showing high expression levels (i.e. above average values) in each cluster are depicted on the right side of the expression profile and the predominant stage (peak of expression) is highlighted in bold. URE and UREg, dormant and germinating urediniospores, respectively; T24 to T168, hours post-inoculation in a time course infection series on poplar leaves inoculated with urediniospores; TEL, telia; BSD, basidia; SPG, spermogonia; and AEC, aecia.

Figure 6. Expression profiles of Melampsora laricipopulina CSP genes in a dormancy exit experimental setting. Reverse transcription-quantitative polymerase chain reaction (RT-qPCR) was performed for MlpCSP1, MlpCSP2 and MlpCSP3 during a time-course dormancy exit series set on poplar leaves. Expression levels were measured in dormant telia collected from poplar leaves maintained in environmental conditions during winter ( $\mathrm{t}$ Oh), in telia incubated in water for $6 \mathrm{~h}$ at room temperature $(\mathrm{t}-6 \mathrm{~h})$, in basidia differentiated from telia after $96 \mathrm{~h}$ at $19^{\circ} \mathrm{C}$ (t-96h_BSD) and in non-vernalized telia after $96 \mathrm{~h}$ at $19^{\circ} \mathrm{C}$ (t-96h_TEL). Mlp-ELF1a was used as a reference gene for the calculation of each transcript expression levels (2- $\Delta \mathrm{Ct})$. For each transcript, expression levels are presented as percentages of the highest level measured (2- $\Delta \Delta \mathrm{Ct})$. Error bars represent standard deviation of the mean from six biological replicates.

Figure 7. Cell growth recovery assay after cold stress exposure in yeast cells expressing Melampsora laricipopulina CSP genes. Yeast cells transformed with plasmids pYES2::MIpCSP1, pYES2::MlpCSP2 and pYES2::MIpCSP3 and empty pYES2 as a control were incubated in an inductive medium for 24 hours at $30^{\circ} \mathrm{C}$. The ability of transformed yeast cells to tolerate cold stress was tested by placing the cells at $-20^{\circ} \mathrm{C}$ during $3,6,9,12$ or 24 hours and back at $30^{\circ} \mathrm{C}$ for 12 hours of further growth. The relative cell densities were measured after the recovering step at $30^{\circ} \mathrm{C}(\mathrm{OD} 600)$ and compared to cell densities before freezing. Values correspond to the mean of three biological replicates and error bars indicate the standard deviation of the mean. 


\section{Tables}

Table 1. Fungal transcription factor families according to their DNA-binding domains (associated PFAM).

\begin{tabular}{|c|c|}
\hline TF gene family name & Associated PFAM (ID: name) \\
\hline AFT & PF08731: Transcription factor, AFT \\
\hline AP2 & PF00847: AP2 domain \\
\hline AT-hook & PF02178: AT-hook, DNA-binding motif \\
\hline BRF1 & PF07741: Brf1-like, TBP-binding domain \\
\hline bZIP & PF00170: bZIP transcription factor; PF07716: Basic-leucine zipper (bZIP) region \\
\hline CBFB-NFYA & PF02045: CCAAT-binding transcription factor (CBF-B/NF-YA), subunit B \\
\hline CBFD_NFYB_HMF & PF00808: Histone-like transcription factor (CBF/NF-Y) and archaeal histone \\
\hline Copper-fist & PF00649: Copper fist DNA-binding domain \\
\hline $\mathrm{CP} 2$ & PF04516: CP2 transcription factor \\
\hline CSD & PF00313: Cold-shock protein (CSP), DNA-binding \\
\hline DDT & PF02791: DDT domain \\
\hline DP & PF08781: Transcription factor, DP \\
\hline DUF4347 & PF14252: Domain of unknown function (DUF4347) \\
\hline DUF702 & PF05142: Domain of unknown function (DUF702) \\
\hline FAR1 & PF03101: FAR1 DNA-binding domain \\
\hline Forkhead & PF00250: Forkhead domain; PF00498: Forkhead-associated (FHA) domain \\
\hline Fungal-trans & $\begin{array}{l}\text { PF04082: Fungal specific transcription factor domain; PF11951: Fungal specific transcription factor } \\
\text { domain }\end{array}$ \\
\hline GCM & PF03615: GCM motif protein \\
\hline GCR1-C & PF12550: Transcriptional activator of glycolytic enzymes \\
\hline HLH & PF00010: Helix-loop-helix DNA-binding domain \\
\hline HMG-box & $\begin{array}{l}\text { PF00505: High mobility group (HMG) box; PF09011: High mobility group (HMG)-box domain; } \\
\text { PF04769: Mating-type protein MAT alpha } 1 \text { HMG-box }\end{array}$ \\
\hline $\begin{array}{l}\text { Homeobox/Homeodom } \\
\text { ain }\end{array}$ & PF00046: Homeobox/Homeodomain; PF05920: Homeobox KN domain \\
\hline HSF DNA-bind & PF00447: Heat shock factor (HSF)-type, DNA-binding \\
\hline HTH & PF01381: Helix-turn-helix; PF13560: Helix-turn-helix domain \\
\hline KilA-N & PF04383: KilA-N domain \\
\hline Myb & $\begin{array}{l}\text { PF00249: Myb-like, DNA-binding domain; PF13837: Myb/SANT-like, DNA-binding domain; PF13921: } \\
\text { Myb-like, DNA-binding domain }\end{array}$ \\
\hline NDT80_PhoG & PF05224: NDT80/PhoG-like, DNA-binding family \\
\hline Not1 & PF04054: CCR4-Not complex component, Not1 \\
\hline NOT2_3_5 & PF04153: NOT2/NOT3/NOT5 family \\
\hline PC4 & PF02229: Transcriptional Coactivator p15 (PC4) \\
\hline PHD & PF00628: PHD-finger; PF13831: PHD-finger \\
\hline PHF5 & PF03660: PHF5-like protein \\
\hline Rap1-DNA-binding & PF09197: Rap1, DNA-binding \\
\hline RFX-DNA-binding & PF02257: RFX DNA-binding domain \\
\hline S1FA & PF04689: DNA-binding protein, S1FA \\
\hline SET & PF00856: SET domain \\
\hline SGT1 & PF07093: SGT1 protein \\
\hline SRF-TF & PF00319: SRF-type transcription factor (DNA-binding and dimerisation domain) \\
\hline
\end{tabular}




\begin{tabular}{|c|c|}
\hline STE & PF02200: STE-like transcription factor \\
\hline T-box & PF00907: T-box \\
\hline TBP & PF00352: Transcription factor, TFIID (or TATA-binding protein, TBP) \\
\hline TEA & PF01285: TEA/ATTS domain \\
\hline Tfb2 & PF03849: Transcription factor, Tfb2 \\
\hline TRAUB & PF08164: Apoptosis-antagonizing transcription factor, C-terminal \\
\hline Vhr1 & PF04001: Transcription factor, Vhr1 \\
\hline WRKY & PF03106: WRKY DNA-binding domain \\
\hline YL1 & PF05764: YL1 nuclear protein \\
\hline $\mathrm{Zf}-\mathrm{C} 2 \mathrm{H} 2$ & $\begin{array}{l}\text { PF00096: Zinc finger, C2H2-type; PF12171: Zinc finger, double-stranded RNA-binding; PF13894: } \\
\text { C2H2-type zinc finger; PF13912: C2H2-type zinc finger; PF13913: Zinc finger, C2HC-type }\end{array}$ \\
\hline $\mathrm{Zf}-\mathrm{C} 3 \mathrm{HC} 4$ & $\begin{array}{l}\text { PF00097: Zinc finger, C3HC4-type (RING finger); PF13920: Zinc finger, C3HC4-type (RING finger); } \\
\text { PF13923: Zinc finger, C3HC4-type (RING finger) }\end{array}$ \\
\hline Zf-C5HC2 & PF02928: C5HC2 zinc finger \\
\hline $\mathrm{Zf}-\mathrm{CCCH}$ & PF00642: Zinc finger C-x8-C-x5-C-x3-H type (and similar) \\
\hline Zf-GATA & PF00320: GATA zinc finger \\
\hline $\mathrm{Zf}-\mathrm{HC} 5 \mathrm{HC} 2 \mathrm{H}$ & PF13771: PHD-like zinc-binding domain; PF13832: PHD-zinc-finger like domain \\
\hline Zf-met & PF12874: Zinc finger,C2H2-type \\
\hline Zf-NF-X1 & PF01422: NF-X1 type zinc finger \\
\hline Zf-TAZ & PF02135: Zinc finger, TAZ \\
\hline Zn cluster & PF00172: Fungal Zn(2)-Cys(6) binuclear cluster domain \\
\hline
\end{tabular}

Table 2. The Top $10 \mathrm{TF}$ families in fungal genomes.

\begin{tabular}{lcc}
\hline \multicolumn{1}{c}{ TF gene family name } & Occurrence $(\mathbf{x 1 0 0 0 )}$ & $\begin{array}{c}\text { TF repertoire } \\
\text { proportion (\%) }\end{array}$ \\
\hline Zn cluster & 130 & 28,07 \\
Fungal-trans & 111 & 24,12 \\
Zf-C2H2 & 45 & 9,83 \\
Zf-C3HC4 & 30 & 6,53 \\
SET & 15 & 3,27 \\
PHD & 15 & 3,18 \\
Myb & 13 & 2,90 \\
Forkhead & 13 & 2,84 \\
bZIP & 13 & 2,83 \\
Zf-CCCH & 12 & 2,63 \\
\hline
\end{tabular}


bioRxiv preprint doi: https://doi.org/10.1101/2021.10.19.465044: this version posted October 19,2021 . The copyright holder for this preprint (which was not certified by peer review) is the author/funder, who has granted bioRxiv a license to display the preprint in perpetuity. It is made available under aCC-BY-NC-ND 4.0 International license.

Table 3. TF families significantly over- or under-represented in Pucciniales related to other fungal taxonomical groups.

\begin{tabular}{|c|c|c|c|}
\hline TF gene family name & Comparison & $\begin{array}{l}\text { Number of } \\
\text { groups }\end{array}$ & Related taxonomical groups* \\
\hline CSD & Over-represented & 3 & $\begin{array}{l}\text { Ascomycota }(P<0,0001) \\
\text { Other_Basidiomycota }(P<0,0001) \\
\text { Ustilaginomycotina }(P<0,0001)\end{array}$ \\
\hline STE & Over-represented & 2 & $\begin{array}{l}\text { Other_Pucciniomycotina }(P<0,001) \\
\text { Ustilaginomycotina }(P<0,0001)\end{array}$ \\
\hline Homeobox/Homeodomain & Over-represented & 1 & Ustilaginomycotina $(P<0,01)$ \\
\hline HSF DNA-bind & Over-represented & 1 & Ascomycota $(P<0,0001)$ \\
\hline PC4 & Under-represented & 3 & $\begin{array}{l}\text { Ascomycota }(P<0,0001) \\
\text { Other_Basidiomycota }(P<0,0001) \text {; } \\
\text { Other_Pucciniomycotina }(P<0,0001)\end{array}$ \\
\hline Forkhead & Under-represented & 2 & $\begin{array}{l}\text { Ascomycota }(P<0,05) \text {; Other_Basidiomycota } \\
(P<0,0001)\end{array}$ \\
\hline $\mathrm{Zf}-\mathrm{C} 2 \mathrm{H} 2$ & Under-represented & 2 & $\begin{array}{l}\text { Ascomycota }(P<0,0001) \\
\text { Other_Basidiomycota }(P<0,05)\end{array}$ \\
\hline bZIP & Under-represented & 1 & Ascomycota $(P<0,05)$ \\
\hline $\mathrm{CP} 2$ & Under-represented & 1 & Ascomycota $(P<0,0001)$ \\
\hline HMG & Under-represented & 1 & Other_Basidiomycota $(P<0,001)$ \\
\hline NDT80_PhoG & Under-represented & 1 & Ascomycota $(P<0,0001)$ \\
\hline $\mathrm{Zf}-\mathrm{CCCH}$ & Under-represented & 1 & Other_Basidiomycota $(P<0,05)$ \\
\hline Zf-GATA & Under-represented & 1 & Other_Basidiomycota $(P<0,001)$ \\
\hline
\end{tabular}

*P-value level after performing a pairwise comparison with a Dunn test (Bonferroni correction) 
- Ascomycota - Other_Basidiomycota Other_Pucciniomycotina - - Pucciniales Ustilaginomycotina

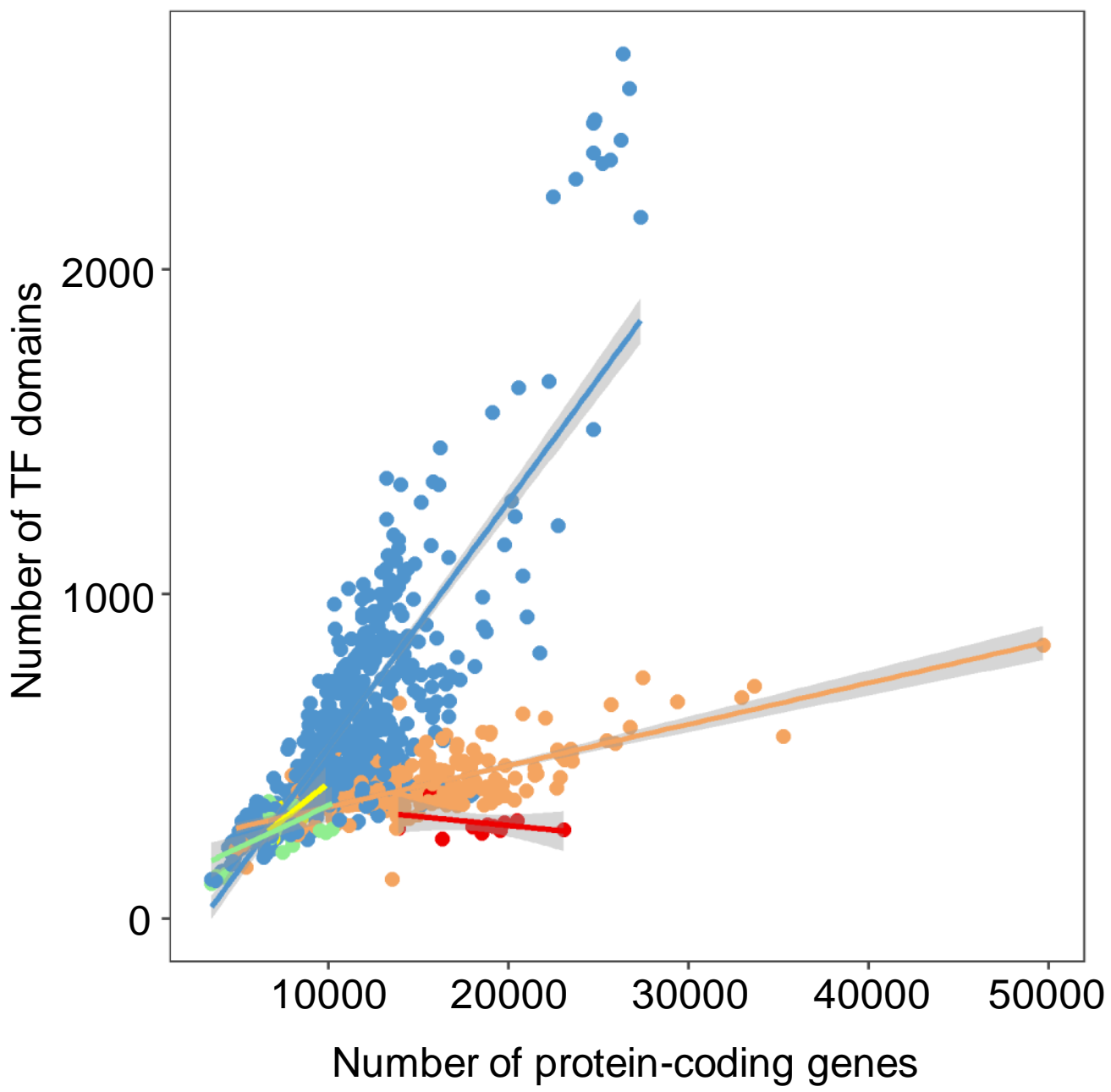




\section{A}

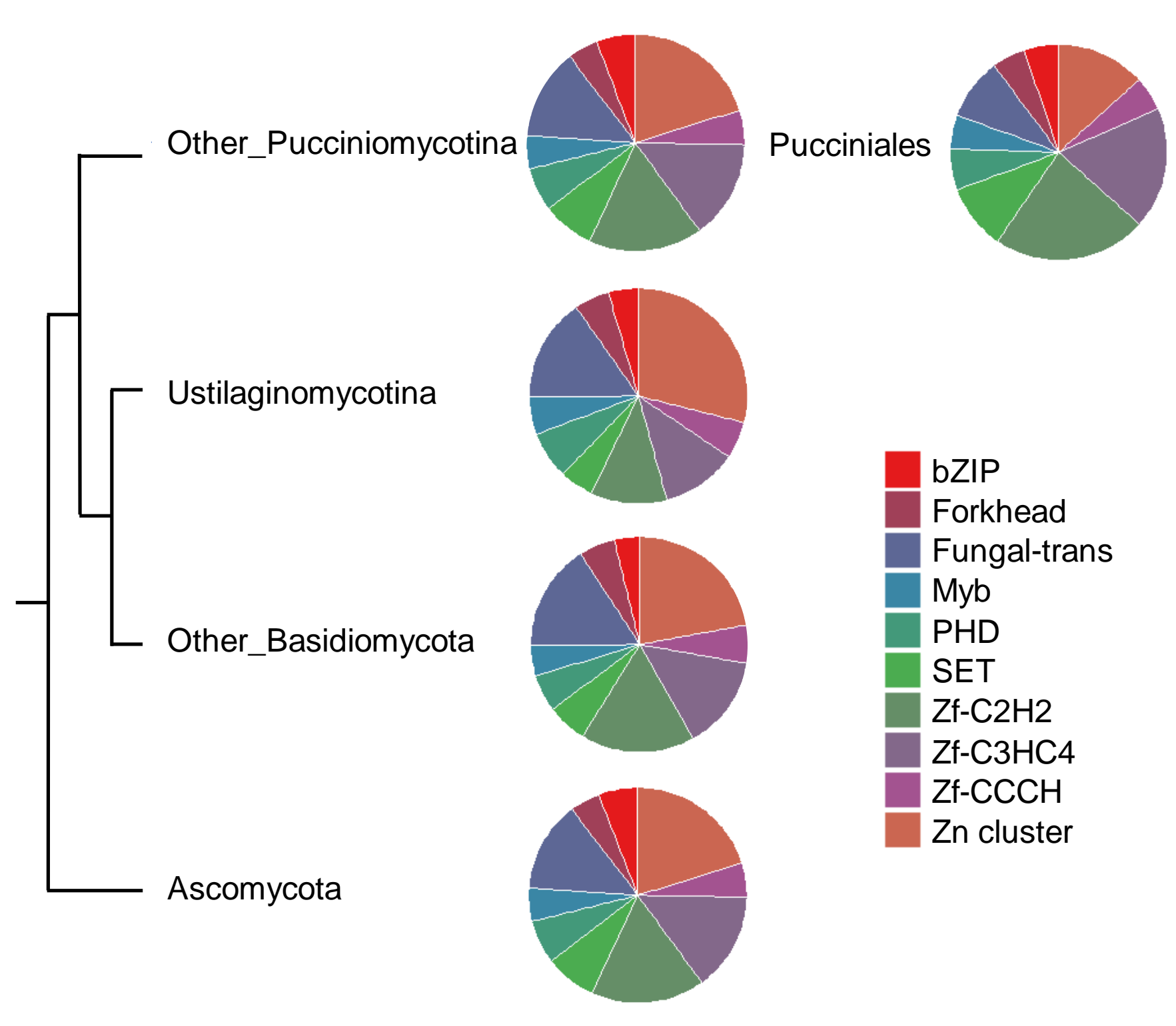

B
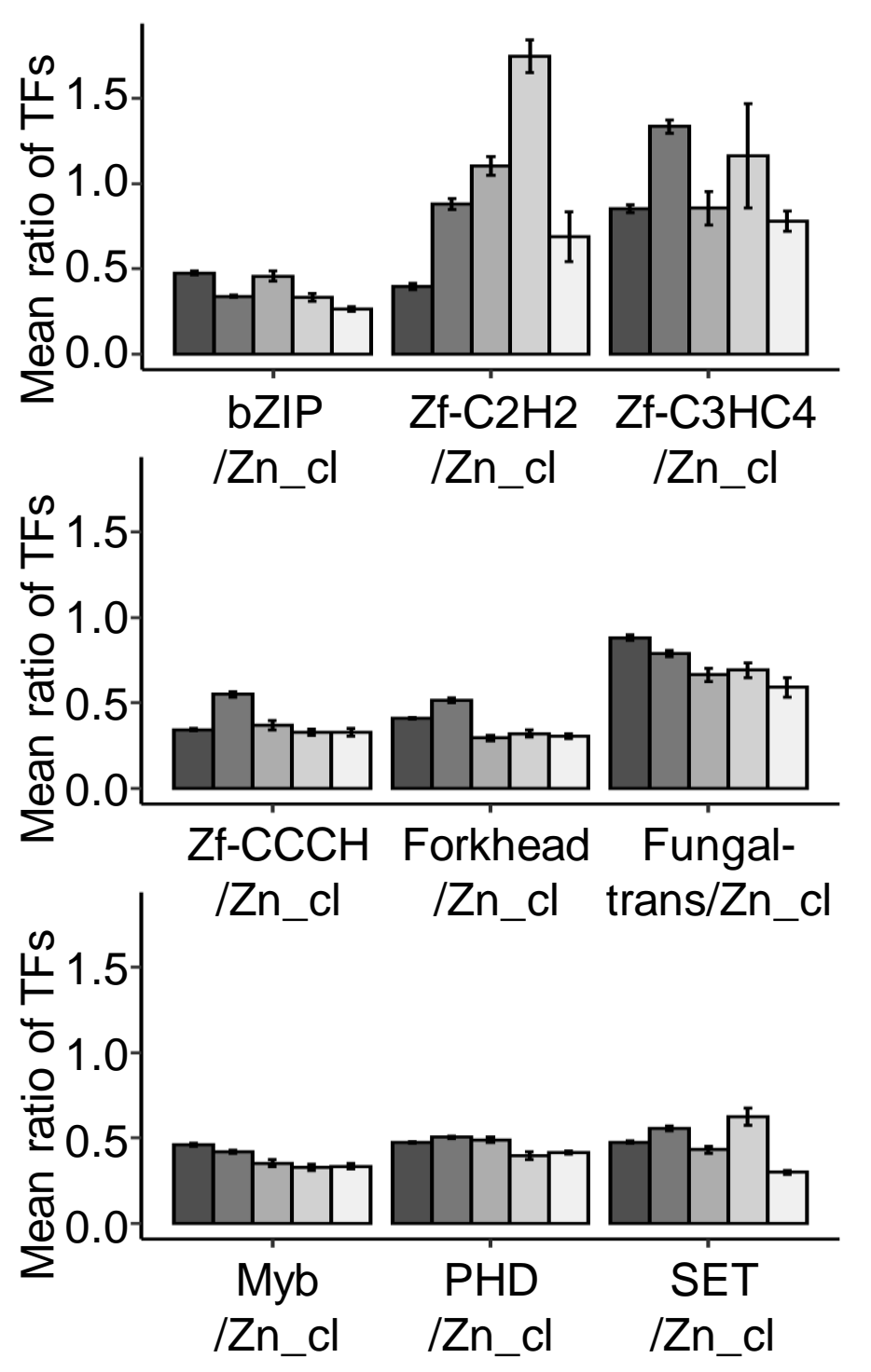

Ascomycota $\square$ Other_Basidiomycota $\square$ Other_Pucciniomycotina $\square$ Pucciniales $\square$ Ustilaginomycotina 


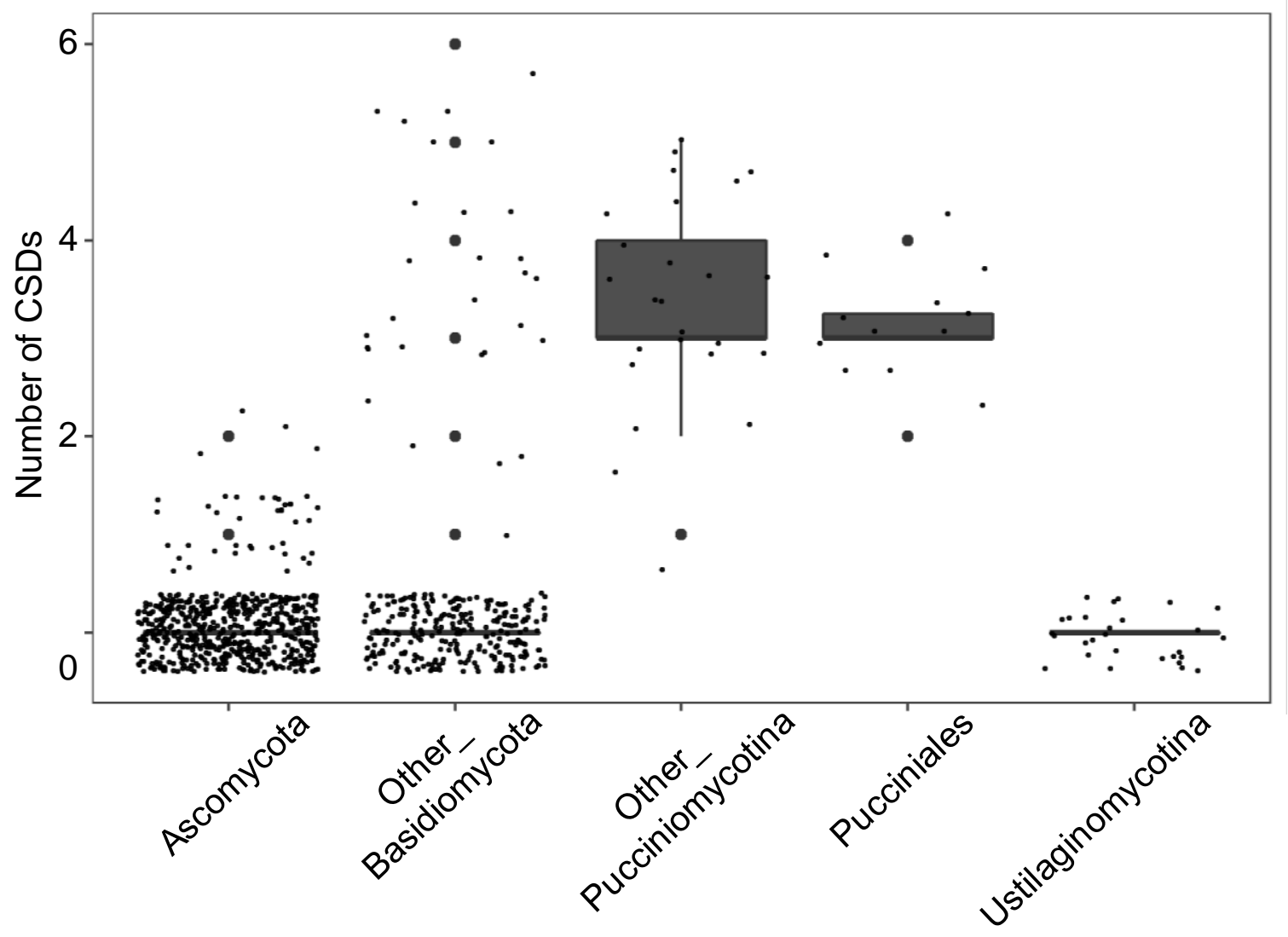




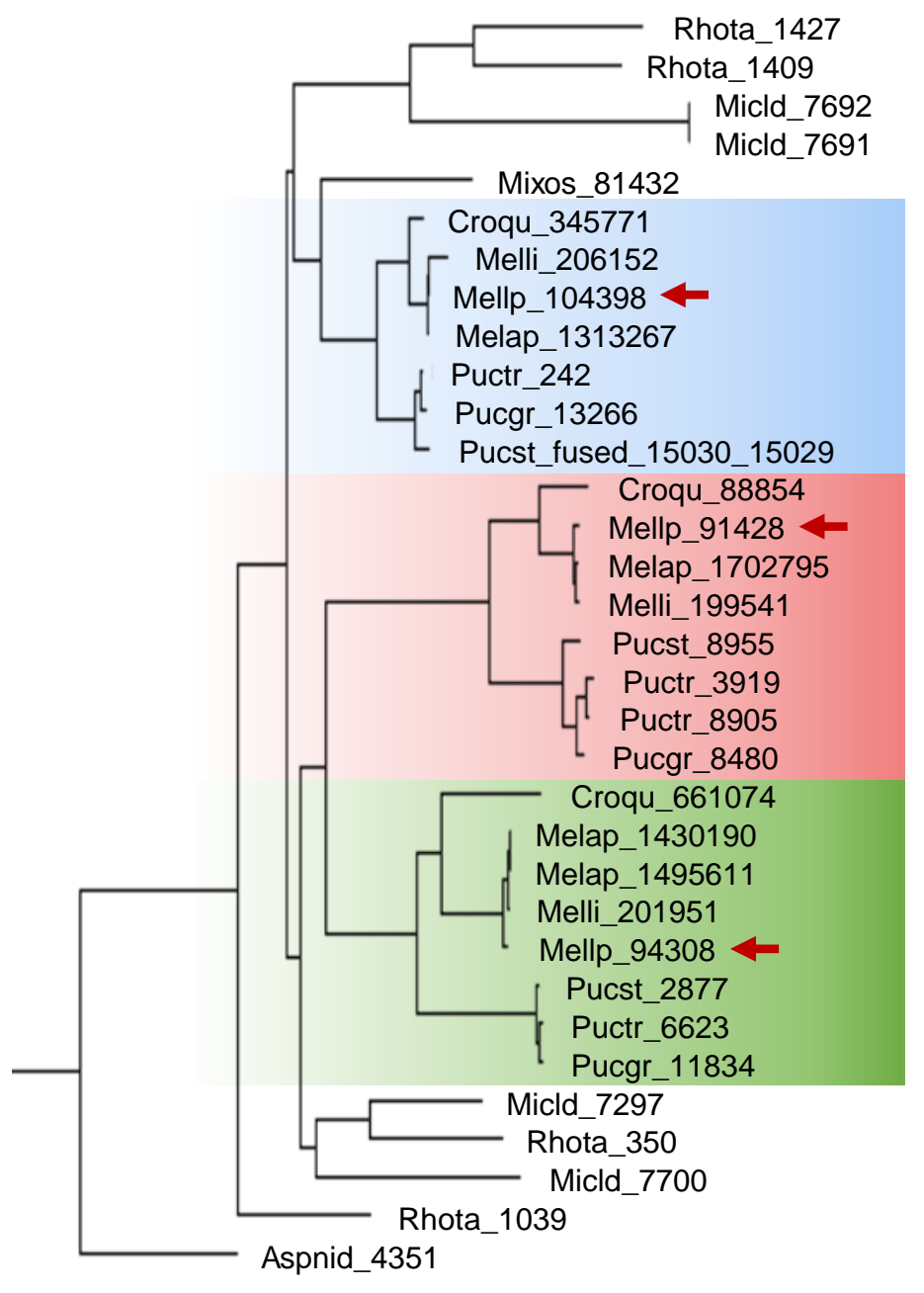

- GT CKFFNPO TGFGY I DDRAEEL - . - . - AT DVFVHFT I KGACKFFDVE|KGFGF I| I DDHAEEL - . . - . GADVFVHYTG I SGK VK FWNM - K GWGY LIVDDHAYEL - - - D - - GRDVFVHHT A I - - - SGK VK FWNM - K GWGY LIVDDHAYEL - - - D - - GRDVFVHHT A I - GVCKFFNTOKGFGF KGVCKFFNSOKGFGF LTAATQTG I ESTSR KGVCKFFNSQKGFGF KGVCKFFNSOKGFGF KGVCKFFNSOKGFGF KGVCKFFNSQKGFGF RGVCKFFNSOKGFGF GRCKMYNCDKGVGF GRCKMYNCD K GVGF GRCKMYNCDKGVGF GRCKMYNCD/KGVGF GRCKMYNCD/KGVGF GRCKMYNCD K GVGF GRCKMYNCD/KGVGF GRCKMYNCD|KGVGF SGTCKFFNVGKGFGF SGFCKFFNAGKGFGF SGFCKFFNAGKGFGF SGFCKFFNAGKGFGF SGFCKFFNAGKGFGF TG I CKFFNVGKGFGF TG I CKFFNVGKGFGF TGVCKFFNVGKGFGF RGVVKFFNS L KGFGF RG I VKFFNS L KGFGFV TGVTKFFNVL KGFGF DSRPEEL - - - - G - - GQE VF VHYT A I NDEHPDEL NDDHPDEL

NDDHPDE L IDDHPDEL NDDHPEEL NDDHPEEL

DDHPEEL

DDDLTEV

DDDLEEV-

PYDVK I HWT

DDDLEEV -

-. - PYDVK I HWT

DDRLDQV . . . . PQDVK I HWT IDRLDQV - . . . . PQDVK I HVT DDRLDQV - PQDVK I HWT I

DSRPDELP I IEGDPGK

QDDNPAE LPTMDGDPGT D I F VHY S

FVHFSC I V - . S DDNP AE LPTMDGDPGT $F \vee H Y$

DDNAELPTMDGDPGT

F VHYS QDDNPAELPTMDGDPGT D I F VHY
KDSRPEELPVLTGDPGT D I FVHY F VHYSC I V.

DSRPEELPVLTGDPGT D I FVHYSS I V -

VDNDPAAL - - - G - - GQEVVCHFIA

RGVKFFNAOKGFGF

DNDPTAL - - -

DHRADEL - - - GT VKWYNDAQGFGF IT SDF
EQSRG - FRCLSPGERVEYFLTQNS AGRVQALKVVG EQLQG - FRCL AQNERVEYT I VKHT SGRFQALKVR RQTGGFFRFL APHERVTYDLL . . . - YKEKKPH RQTGGFFRFLAPHERVTYDLL . . . . YKEKKPH HGKGG - FKS L AEGEE VEYE VNAGQKG - FT AANVTG - GGKGG - FRSLAEGEE VEYVVSPGQKG - FQATEVTG GGKGG - FRS L AEGEE VEY VVSPGHKG - FQATE VTG GGKGG - FRSLAEGEE VEY VVSPGHKG - FQATE VTG GGKGG - FRSL AEGEE VEYVVSPGHKG - FQATEVTG - $G G K G G$ - FRSLAEGE
- ESKGN - FRSL AEGEE VEYVVAPGQKG - FQATE VTG ESKGN - FRSL AEGEE VEY VVAPGQKG - FQATEVTG EGRGN - FRSLAEGEE VEY VVAT GQKG - FQATE VTG YSDQE - FKSLAKGE VVEYT LNLT ANG - YSASYVTG YSDQE - FKSL AKGE VVEYTLNLTSNG - YSASYVTG YSDQE - FKSLAKGE VVEYT LNLTSNG - YS ASY VTG YSDQE - FKSL AKGE VVEYTLNLTSNG - YSASYVTG FSDQE - FKSL AKGE I VEYT LN I TANG - YSASY VTG FSDQE - FKSLAKGE I VEYT LN I T ANG - YSASY VTG FSDQE - FKSLAKGE I VEYT LN I TANG - YSASY VTG FSDQE - FKSL AKGE I VEYTLN I TANG - YSASY VTG SCQS A - YKSLLDGES VEY I LGRSNKG - LAALD I TG RCDAG - FKSLLDGEKVEY I LGRSNKG - LAALD I TG RCDAG - FKS LLDGEKVEY I LGRSNKG - LAALD I TG RCDAG - FKS L LDGEKVEY I LGRSNKG - LAALD I TG RCDAG - FKSLLDGEKVEYVLGRSNKG - LAALD I TG SCDAP - YKSLLDGE I VEYYLGRSNKG - LAALE I TG SCDAP - YKSLLDGE I VEYYLGRSNKG - LAALE I TG SCDAP - YKSLLDGE VVEYYLGRSNKG - LAALE I TG

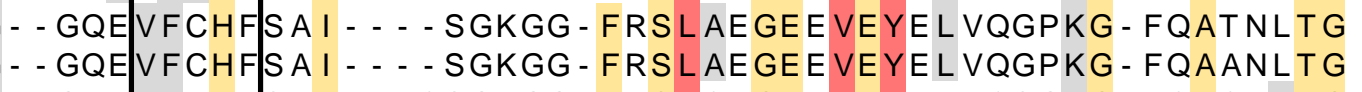
- GDEVFVHYSA I E AVQSGTGG - FRSLQEGE L VEYN I VCSGKG - FQAQNVTG - GVEVFVHYT A I TS VKGGPNG - FKSL AEGENVEYS I APGPKG - WQAQNVT - GGEL I LRRQS I - - - - TEH - TQRLKEGMKVSYE A VHLPML - LMAEQV - 


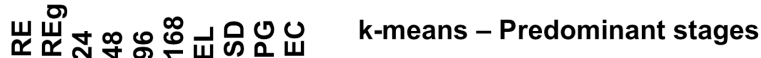

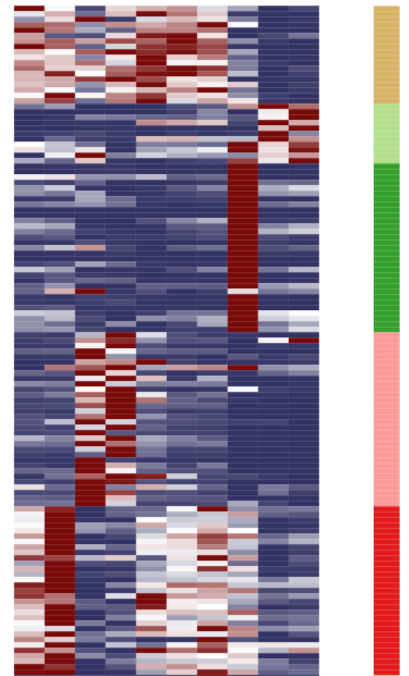

k1 - Uredinia, poplar in planta stages, telia and basidia

k2 - Larch in planta stages

k3 - Basidia

k4 - Poplar in planta early stages

k5 - Uredinia, poplar in planta late stages, telia and basidia

k6 - Poplar in planta late stage (sporulation $168 \mathrm{hpi}$ ) and telia k7 - Poplar in planta late stage (biotrophic growth 96hpi)

k8 - Uredinia, poplar in planta and telia

k9 - Poplar in planta late stage (sporulation 168hpi)

k10 - Uredinia, poplar in planta late stages, telia, basidia, larch in planta stages 

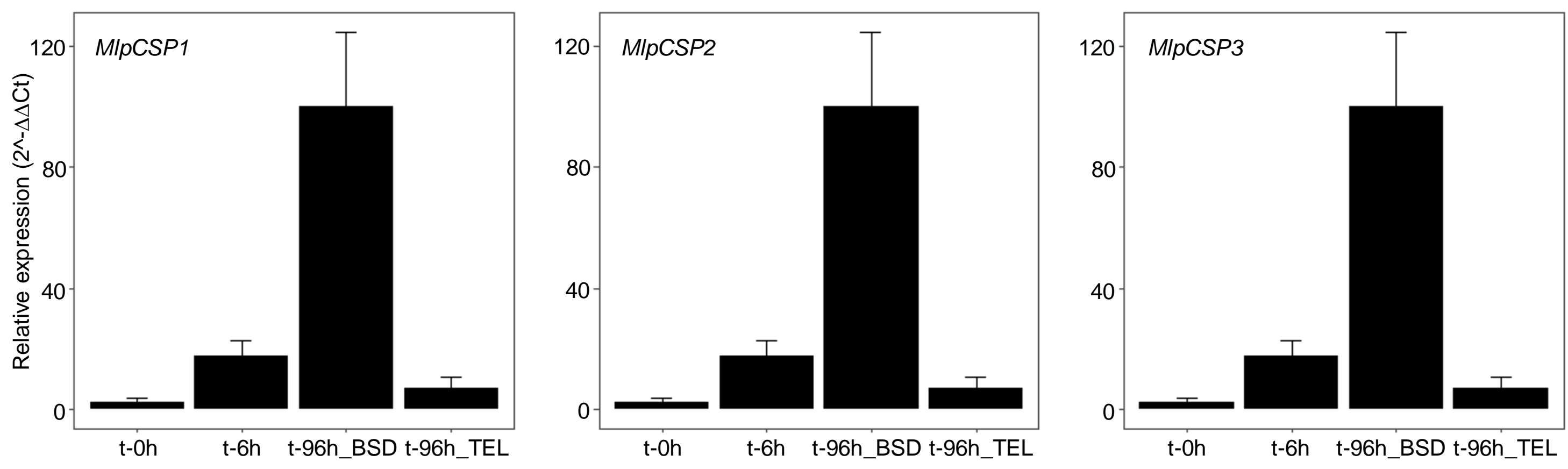
